\title{
The Consequences of Co-benefits for the Efficient Design of Carbon Sequestration Programs
}

\author{
Hongli Feng and Catherine L. Kling
}

Working Paper 05-WP 390

March 2005

\author{
Center for Agricultural and Rural Development \\ lowa State University \\ Ames, lowa 50011-1070 \\ www.card.iastate.edu
}

Hongli Feng is an associate scientist at the Center for Agricultural and Rural Development (CARD); Catherine Kling is a professor in the Department of Economics at lowa State University and head of the Resource and Environmental Policy Division at CARD.

The authors appreciate the significant and careful computational assistance of Todd Campbell. We also appreciate the valuable help of Phil Gassman on environmental modeling. All errors and lack of clarity are our responsibility. For more information on the carbon sequestration work on the Upper Mississippi River Basin discussed herein, visit http://www.card.iastate.edu/environment/carbon/.

This paper is available online on the CARD Web site: www.card.iastate.edu. Permission is granted to reproduce this information with appropriate attribution to the authors.

For questions or comments about the contents of this paper, please contact Hongli Feng, 560D Heady Hall, lowa State University, Ames, IA 50011-1070; Ph: 515-294-6307; Fax: 515-294-6336; E-mail: hfeng@iastate.edu.

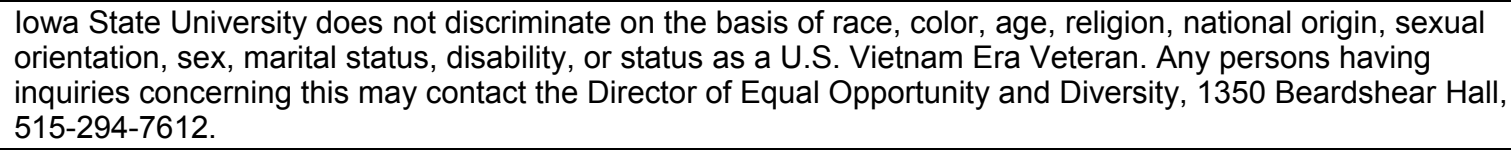




\begin{abstract}
In this paper, we study the social efficiency of private carbon markets that include trading in agricultural soil carbon sequestration when there are significant co-benefits (positive environmental externalities) associated with the practices that sequester carbon. Likewise, we investigate the efficiency of government-run conservation programs that are designed to promote a broad array of environmental attributes (both carbon sequestration and its co-benefits) for the supply of carbon. Finally, policy design and efficiency issues associated with the potential interplay between a private carbon market and a government conservation program are studied. Empirical analyses for an area that represents a significant potential source of carbon sequestration and its associated co-benefits illustrate the magnitude and complexity of these issues in real-world policy design.
\end{abstract}

Keywords: average ranking of benefits, carbon markets, carbon sequestration, cobenefits, conservation programs, the Upper Mississippi River Basin. 


\section{The Consequences of Co-benefits for the Efficient Design of Carbon Sequestration Programs}

\section{Introduction}

A substantial body of literature has developed that assesses the technological basis for, and potential magnitude of, storing or "sequestering" carbon in agricultural soils (Lal et al. 1998). By sequestering carbon in agricultural soils or other sinks, carbon is kept out of the atmosphere and thus does not contribute to the rise of atmospheric greenhouse gas concentrations. The cost-effectiveness of sinks, which has been the subject of many studies (e.g., McCarl and Schneider 2001), will determine to what extent sinks can contribute to the efforts on the mitigation of global climate change. Other characteristics of sinks, including the non-permanence and the co-benefits issues, and the characteristics of greenhouse gas (GHG) emissions reduction policies in general will determine how sinks are to be utilized in the portfolio of climate mitigation.

There are three categories of instruments that have been discussed to reduce GHG emissions from sources like energy companies: standards, carbon (or GHG emission) taxes, and a cap-and-trade style permit trading system. With either taxes or standards, firms would have little flexibility but would have to meet the standards or pay the taxes as required. Under a cap-and-trade system firms would be allocated a certain number of permits to emit GHGs and then would be allowed to sell (or buy) permits if their actual emissions were less (or more) than their initial allocation. While some countries (e.g., Italy and Sweden) have adopted carbon or related taxes (Ikins and Barker 2001), emissions trading is the instrument being most intensively discussed and has been proposed in a number of countries/regions that have ratified the Kyoto Protocol, including Canada's domestic emission trading system and the European Union's emission trading scheme.

If standards and taxes were adopted as the instrument of choice for controlling the emissions of GHGs from sources, then carbon sequestered in agriculture or forestry could be used to lessen the overall need to reduce carbon emissions. In the context of agree- 
ments such as the Kyoto Protocol, this could mean allowing countries to reduce their total mitigation obligations by subtracting the total amount of carbon sequestration from their agreed-to reductions in emissions. Thus, a country that increased its carbon sequestration levels could levy lower taxes or impose less stringent emission standards. While the reduction of the total mitigation obligation or goal could also be applied if the instrument of a trading system were implemented, there would also be the opportunity to include contributions to carbon sinks directly into an emissions trading system. For example, a farmer who adopts a practice that sequesters carbon in his soil could be credited with an emission reduction and then sell that credit directly on the emissions market. In fact, one of the cornerstone elements of Canada's climate change plan is to include an offset system allowing the participation of carbon sinks into its domestic emission trading system (Thomassin 2003).

The characteristics of carbon sinks will determine the economic efficiency of offsetting GHG emission by sinks in a carbon market. Carbon sequestration has a number of special features that have been addressed in the literature, including its lack of guaranteed permanence (Feng, Zhao, and Kling 2002) and the design of contracts to deal with this non-permanence issue (Sedjo and Marland 2003). Another issue relates to the size of individual suppliers of carbon sequestration. If the amount of carbon sequestered by each individual agricultural producer is large enough such that the potential gain of market trading can offset transaction costs, then agricultural producers can participate in the market and make transactions themselves.

However, studies have shown that this is unlikely to be the case, and intermediaries who aggregate carbon from a variety of suppliers have already begun developing. A study prepared for some Canadian agencies, including the Canadian Forest Service (Reedy 2003), indicated that large companies request a minimum purchase or transaction unit of 100,000 metric tons, while small private landowners may have less than 600 metric tons of carbon credits to sell annually. According to Butt and McCarl (2004), the Chicago Climate Exchange has guidelines that require an entering group to represent at least 10,000 metric tons of carbon. Among the likely aggregators are existing farmers' organizations, brokerage firms, and the government. The Iowa Farm Bureau launched a four-year pilot program to begin aggregating carbon credits by enrolling farmers who use 
conservation tillage practices or permanent grass cover (Iowa Farm Bureau 2005). ${ }^{1}$ As we show in the paper, such aggregation will have implications for the efficiency of carbon markets.

While inclusion in carbon markets has been discussed as a policy approach for taking advantage of agricultural sequestration to contribute to lower atmospheric concentrations, there are other policy instruments that could potentially achieve similar results. In particular, conservation payments (also known as "green" payments) have received some mention as a possible approach for inducing additional carbon storage in soils. In fact, some major conservation policies already make payments to farmers for the adoption/maintenance of conservation practices with large carbon sequestration potential, for example, the Rural Environmental Protection Schemes in the European Union, and the Conservation Reserve Program (CRP) and the Environmental Incentive Quality Program in the United States. The CRP is estimated to be sequestering from 7.6 to 11.5 million metric tons of carbon equivalence annually (Follett, Kimble, and Lal 2001).

In this paper, we consider both carbon markets and conservation programs as policies to sequester carbon in agricultural soils through the adoption of conservation practices, such as the retirement of agricultural land from cropland. The efficiency of carbon markets and the interaction of the two programs will be the focus of the paper. In particular, we focus on how co-benefits, which are externalities in carbon markets, affect social efficiency. While a number of studies have addressed the potential empirical magnitude of these co-benefits in both agricultural soils sequestration and forest biomass (e.g., Plantinga and Wu 2003 and McCarl and Schneider 2001), we take a different view of the issue by focusing on the implications for the efficient choice and design of a policy to induce carbon sequestration. In particular, we consider the consequences of co-benefits from carbon sequestration on the efficient level of sequestration activities relative to emission reductions.

We first examine how co-benefits affect the efficiency of a free, well-functioning carbon market. The implication of spatial heterogeneity is explored in section 2.2. Then, in section 3.1 we present the empirical characteristics of co-benefits in our study region. In the next sub-section, we discuss the implications of these characteristics on the outcomes of a carbon market and a conservation program implemented in each other's 
absence. In section 3.3, we discuss several issues related to policy design when carbon markets and conservation programs co-exist. Conclusions are provided in section 4 .

\section{How Co-benefits Affect the Efficient Sequestration and Emission Reduction Levels}

When sequestered carbon is treated as an emission reduction credit and is traded in the carbon market, co-benefits are externalities. It is well known in economic theory that Pareto-optimal allocations will not, in general, be achieved by free-market forces when there are externalities. However, government intervention is not necessarily warranted, especially if the magnitude of the externality is small and transaction costs are present. In addition to size, there are other factors that determine the socially efficient levels of carbon sequestration in the presence of externalities. We discuss two such factors here: co-benefits from carbon emission reductions and spatial heterogeneity in the externalities.

\subsection{The Effects of Co-benefits from Carbon Sequestration When There Are Also Co-benefits from Carbon Emission Reductions}

In a carbon trading market that includes emission reduction credits for carbon sequestration, permanent carbon emission reductions, such as those produced by lowering fossil fuel use, can be traded with carbon sequestration credits. Of relevance to the question of the efficient allocation of emission reductions versus sequestration is the fact that carbon emission reductions are also believed to have significant co-benefits (Burtraw et al. 2003). One important form of these co-benefits is a reduction of local air pollutants such as NOx and volatile organic compounds. Thus, economic efficiency in the use of carbon sequestration depends both on the co-benefits of carbon sequestration and carbon emission reductions.

To be more concrete, suppose a nation plans to reduce its carbon emissions by a goal of X tons, which may be the nation's obligation under some international treaty or a selfimposed goal. Both sequestration and emission reduction will be utilized to achieve the goal at the least cost (which includes the cost of carbon reduction and the associated cobenefits). Denote carbon sequestration in the nation as $X_{1}$ and the co-benefits generated in the sequestration of $X_{1}$ as $g_{1}\left(X_{1}\right)$. Similarly, let the emission reduction in the nation be $\mathrm{X}_{2}$, and the corresponding co-benefits be $\mathrm{g}_{2}\left(\mathrm{X}_{2}\right)$. The cost of carbon sequestration and 
emission reduction are represented by concave functions: $f_{1}\left(X_{1}\right)$ and $f_{2}\left(X_{2}\right)$, respectively. Then, the nation's problem would be as follows:

$$
\begin{aligned}
& \min _{X_{1}, X_{2}} f_{1}\left(X_{1}\right)-g_{1}\left(X_{1}\right)+f_{2}\left(X_{2}\right)-g_{2}\left(X_{2}\right) \\
& \text { such that } X_{1}+X_{2}=X .
\end{aligned}
$$

The first-order condition of this problem is

$$
f_{1}^{\prime}\left(X_{1}^{*}\right)-f_{2}{ }^{\prime}\left(X_{2}^{*}\right)=g_{1}{ }^{\prime}\left(X_{1}^{*}\right)-g_{2}{ }^{\prime}\left(X_{2}^{*}\right),
$$

where an apostrophe indicates the first derivative of a function and an asterisk indicates the optimal solution. The left side of equation (2) is the difference between the marginal cost of carbon sequestration and emission reduction and the right side of the equation represents the difference between the marginal co-benefits of carbon sequestration and emission reduction. Equation (2) requires that the two differences be equal in order to achieve $\mathrm{X}$ at the least cost.

On the other hand, a free market for carbon trading can be expected to disregard the co-benefits, that is, $g_{1}\left(X_{1}\right)$ and $g_{2}\left(X_{2}\right)$. It is well known that market forces will theoretically achieve the least-cost solution, although the least cost only refers to carbon sequestration disregarding co-benefits. Consequently, a free market would result in

$$
f_{1}^{\prime}\left(\tilde{X}_{1}\right)-f_{2}^{\prime}\left(\tilde{X}_{2}\right)=0
$$

that is, the marginal cost of sequestration would equal the marginal cost of emission reductions. Comparing equations (2) and (3), it is clear there is a special case wherein the free market solution will also be the socially optimal solution. The condition for this to happen is that the right sides of (2) and (3) are equal, or

$$
g_{1}^{\prime}\left(X_{1}^{*}\right)=g_{2}{ }^{\prime}\left(X_{2}^{*}\right) \text {. }
$$

In other words, it requires that the marginal co-benefits from sequestration exactly equal the marginal co-benefits from emission reductions at the optimal solution.

The situation can be illustrated graphically as in Figure 1, where the solid curves represent the marginal costs and the dashed curves represent the marginal costs net of the corresponding co-benefits. The distance between the solid curve (e.g., $\left.f_{1}^{\prime}\left(X_{1}\right)\right)$ and the corresponding dashed curve (e.g., $\left.f_{1}{ }^{\prime}\left(X_{1}\right)-g_{1}{ }^{\prime}\left(X_{1}\right)\right)$ is the marginal co-benefits (e.g., 


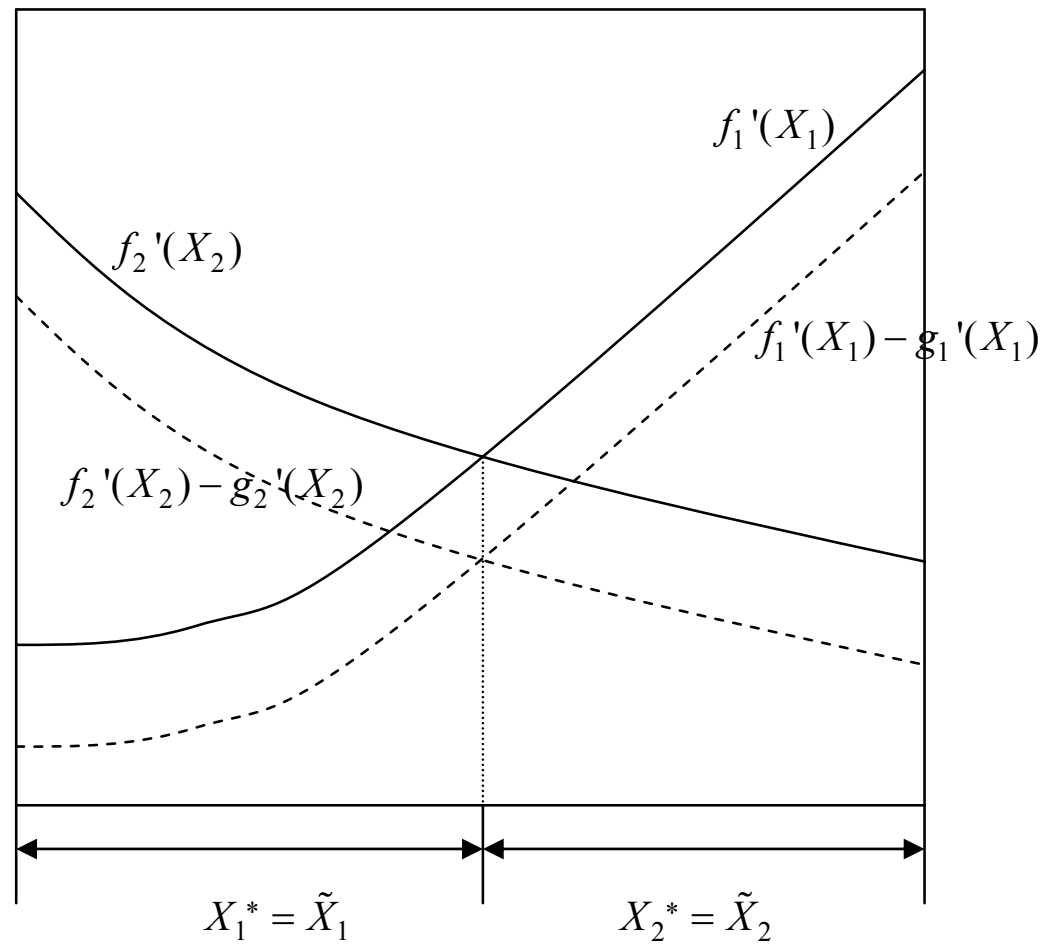

FIGURE 1. The effects of co-benefits in sequestration and emission reduction

$\left.g_{1}{ }^{\prime}\left(X_{1}\right)\right)$. The figure illustrates a situation where the marginal co-benefits are such that the free-market solutions are also socially optimal.

It is important to point out that the horizontal axis measures the total emission reduction level, X. As such, as the target is adjusted, one of the vertical axes will shift outward (or inward) to accommodate a higher (or lower) carbon reduction goal. This implies that the solid lines will have a different intersection point, as will the dashed lines. In order for the two intersection points to be vertically aligned for all emission reduction goals (thereby projecting to the same point on the horizontal axis), the distance between the two solid curves and their corresponding dashed curve must be equal for all levels of $\mathrm{X}_{1}$ and $\mathrm{X}_{2}$. Mathematically, both equations (2) and (3) will imply different solutions as $\mathrm{X}$ changes. In order for $X_{1}{ }^{*}=\tilde{X}_{1}$ and $X_{2}{ }^{*}=\tilde{X}_{2}$ regardless of the level of total emission reductions, equation (4) must hold at all levels of $X_{1}$. For this reason, the condition for a free market to achieve socially optimal results in the presence of externalities is not likely to hold in general. 


\subsection{The Effects of Co-benefits in the Presence of Spatial Heterogeneity}

A second complication in the efficient allocation of carbon sequestration and emission reductions when there are co-benefits arises because the magnitude and value of the co-benefits are likely to be highly spatially distinct. While Figure 1 is helpful heuristically, it implies that the co-benefits associated with carbon sequestration and carbon emission reductions are independent of the location or the conservation practice chosen to sequester carbon at the field level, as the cost function $\mathrm{f}_{1}\left(\mathrm{X}_{1}\right)$ represents a national supply curve for carbon sequestration. However, the supply of sequestered carbon is generated by the actions of numerous individual farmers whose fields may have different soil characteristics and weather conditions, and who may choose to undertake very different conservation practices to generate sequestered carbon (conservation tillage versus row cropping for example). As a result, it is very likely that the co-benefit curve would not be as smooth as shown in Figure 1.

To illustrate the issues related to the derivation of the co-benefit supply curve under heterogeneity, we develop a simple framework to derive the supply curve of carbon sequestration and the related environmental benefits. Suppose there are N agricultural or forest fields that can potentially be enrolled for some carbon sequestration practice for some period of time. The annual average carbon sequestered over this interval of time is $c_{n}$ per acre, where $\mathrm{n}$ is the index of a field. The size of field $\mathrm{n}$ is denoted as $A_{n}$ acres. Denote the annual cost of enrolling land from field $\mathrm{n}$ as $p_{n}$ per acre, which is the profit forgone and/or establishment expenditures due to the adoption of the carbon sequestration practice. The co-benefits associated with carbon sequestration from field $\mathrm{n}$ are denoted by $x_{n}{ }^{k}$, where $\mathrm{k}=1,2, \ldots \mathrm{K}$, and $\mathrm{K}$ is the total number of co-benefits from the carbon sequestration activities adopted on field $\mathrm{n}$. The overall co-benefits from field $\mathrm{n}$ is represented by a function of the various environmental benefits from field $\mathrm{n} h\left(c_{n}, \boldsymbol{x}_{n}\right)$, where the vector $\boldsymbol{x}_{n}=\left\{x_{n}{ }^{1}, x_{n}{ }^{2}, \ldots x_{n}{ }^{K}\right\}$. The function $\mathrm{h}($.$) is a very general benefit func-$ tion: it can represent a single benefit such as erosion reduction, or a combination of environmental indicators.

As we mentioned previously, a well-functioning free market will theoretically achieve the least cost disregarding co-benefits. Thus, we can solve the following problem 
to derive the supply curve of carbon sequestration resulting from the effective operation of a free carbon market: choose the number of acres, $a_{n}$, for each field to adopt carbon sequestering practices to minimize the total costs of achieving a certain carbon goal, C, which is the sum of the carbon sequestration from all fields that receive payments.

Mathematically, the problem can be written as

$$
\begin{aligned}
& \min _{a_{n}} \sum_{n} p_{n} \bullet a_{n} \\
& \text { such that } \sum_{n} c_{n} \bullet a_{n}=C \text {, and } 0 \leq a_{n} \leq A_{n} .
\end{aligned}
$$

The solution to problem (5) can be written in a simple form:

$$
\begin{aligned}
& \text { if } \frac{p_{n}}{c_{n}}<\lambda, \text { then } a_{n}^{*}=A_{n} \\
& \text { if } \frac{p_{n}}{c_{n}}>\lambda, \text { then } a_{n}^{*}=0 ; \\
& \text { if } \frac{p_{n}}{c_{n}}=\lambda \text {, then } a_{n}^{*}=\hat{a} ;
\end{aligned}
$$

where $\lambda$ is the Lagrange multiplier of the constraint on total carbon. Heuristically, all fields that have a price-to-carbon ratio below the cut-off level of $\lambda$ will have carbonsequestering conservation practices implemented on the entire acreage; all fields with a price-to-carbon ratio above this level will be devoid of carbon sequestering practices. We use $\hat{n}$ to specifically denote the marginal field such that $\frac{p_{\hat{n}}}{c_{\hat{n}}}=\lambda$. The optimal number of acres to be enrolled from field $\hat{n}$ is determined as follows: $\hat{a}=\left(C-\sum_{\left\{i: a_{i}{ }^{*}=A_{n}\right\}} a_{i}{ }^{*} \cdot c_{i}\right) / c_{\hat{n}}$, where $\left\{i: a_{i}{ }^{*}=A_{n}\right\}$ is the set of fields that are completely enrolled in the program.

The conditions in (6) indicate that the supply of carbon can be thought of as choosing fields with the lowest cost and then moving to those with higher cost. This continues until the carbon target is reached. Thus, the price of obtaining carbon from the marginal field, $\hat{n}$, is the marginal cost of reaching the target $\mathrm{C}$. Obviously, as $\mathrm{C}$ changes, $\hat{n}$ also varies, which implies that the marginal cost of reaching $\mathrm{C}$ likewise changes. By plotting the 
marginal cost on the vertical axis and the corresponding total carbon achieved on the horizontal axis, we obtain the carbon supply curve.

We refer to the co-benefits from the marginal field as the marginal co-benefits for achieving the targeted carbon level. From the previous discussion, it is clear that as $\mathrm{C}$ increases, more fields will be enrolled. Since the enrollment goes from the least expensive to the most expensive (per ton of carbon), the marginal cost of achieving $\mathrm{C}$ also increases. However, since the enrollment is not based on the co-benefits of carbon sequestration, there is no reason to expect that the marginal co-benefits will be increasing as well.

This issue is important because it determines whether carbon markets will "select" the same set of fields as a conservation program would select based on both carbon and co-benefits. If the situation is as illustrated in Figure 1, then both carbon markets and conservation programs will enroll the same set of fields for any given carbon goal, by moving from the left-hand side of Figure 1. In other words, if the magnitude of carbon sequestration and its co-benefits are highly positively correlated (fields that generate large carbon benefits also generate high co-benefits) then it is likely that carbon markets and conservation programs will enroll the same land and there will be relatively small efficiency losses from using a carbon market to generate carbon sequestration in the presence of spatially heterogeneous co-benefits. The sign and degree of correlation between carbon sequestration and its co-benefits is an empirical question that we explore in the next section.

However, before turning to the empirical question, we note that since the amount of carbon sequestration achieved by any given field or farm is likely to be small, there is considerable discussion of aggregating carbon as a way to reduce transaction costs, as we discussed in the introduction. Interestingly, the existence of aggregators in private carbon markets may actually increase the likelihood with which social efficiency is achieved in the presence of co-benefits.

Specifically, suppose fields are aggregated into groups based on the marginal cost of carbon sequestration, $\frac{p_{n}}{c_{n}}$. More specifically, suppose that the marginal costs of the fields in a group are either all below or all above the marginal costs in other groups. 
Operationally, we can group the fields as follows. Rank the fields by $\frac{p_{n}}{c_{n}}$ from the lowest to the highest. Let the first 1 to $m_{1}$ fields form group 1 , denoted as $G_{1}$, and let the fields with rankings from $m_{1}+1$ to $m_{1}+m_{2}$ form the second group, denoted as $G_{2}$. In a similar way, gather the rest of the fields in groups $G_{3}, G_{4}, \ldots G_{L}$, where $\mathrm{L}$ is the total number of groups. Then the total cost of carbon sequestration and the total amount of carbon sequestered by group $\mathrm{i}$ is

$$
G p_{i} \equiv \sum_{\{n: \text { field } n \text { is in group i }\}} p_{n} \text { and } G c_{i} \equiv \sum_{\{n: \text { field } n \text { is in group i }\}} c_{n},
$$

respectively. Similarly, the total amount of overall co-benefits that can be achieved by group i is $G h_{i} \equiv \sum_{\{n: \text { field } n \text { is in group i }\}} h\left(c_{n}, \boldsymbol{x}_{n}\right)$. Then it is trivial to show that

RESULT 1 . For all $i, j=1,2, \ldots L$, if $G h_{i}=\mathrm{z} \bullet G c_{i}$, where $z$ is a positive constant, then

$$
\frac{G p_{i}}{G h_{i}} \geq \frac{G p_{j}}{G h_{j}} \text { iff } \frac{G p_{i}}{G c_{i}} \geq \frac{G p_{j}}{G c_{j}}
$$

This is a simple, smoothing result, but it has a very interesting implication. It indicates that the order in which a carbon market would purchase sequestration from groups can be the same order that it would be efficient to achieve both carbon and co-benefits. This can happen even if individual fields within a group have co-benefits that are not perfectly correlated with carbon benefits. For this to happen, the grouping has to satisfy the condition that the co-benefits are a positive, constant multiple of the carbon benefits from the group. Simply put, Result 1 implies that, under the condition specified in the result, private markets will yield socially efficient co-benefit choices. ${ }^{2}$ We will examine the linearity condition in Result 1 in the empirical section.

\section{An Application to Carbon Sequestration and Co-benefits from Land Retirement}

To illustrate the foregoing concepts, we examine carbon sequestration in the Upper Mississippi River Basin (UMRB), a large watershed that covers 189,000 square miles in 
the north-central part of the United States (see Figure 2). Other studies have demonstrated that this region has a significant potential for carbon sequestration from agricultural soils using practices such as conservation tillage and removal of land from active crop production (and instead being planted in perennial grasses or other native vegetation). This area also suffers from significant water quality degradation, and agricultural practices that sequester carbon in the soil are often also identified as potentially valuable contributors to improving local and regional water quality. More specifically, land retirement reduces both phosphorous and nitrogen loading, the two key sources of nutrient impairment in the region, and it also reduces soil erosion. The practice of conservation tillage reduces the amount of erosion from soils, which reduces phosphorous loading and may have nitrogen benefits as well.

In this example, we will focus on the sequestration practice of land retirement with planting of perennial grasses, the most common CRP practice in the region. As of 1997, the region contained over 3,000,000 acres of land enrolled in the CRP, with a total annual payment of about $\$ 277,500,000$ (estimated with the rental payment information of the

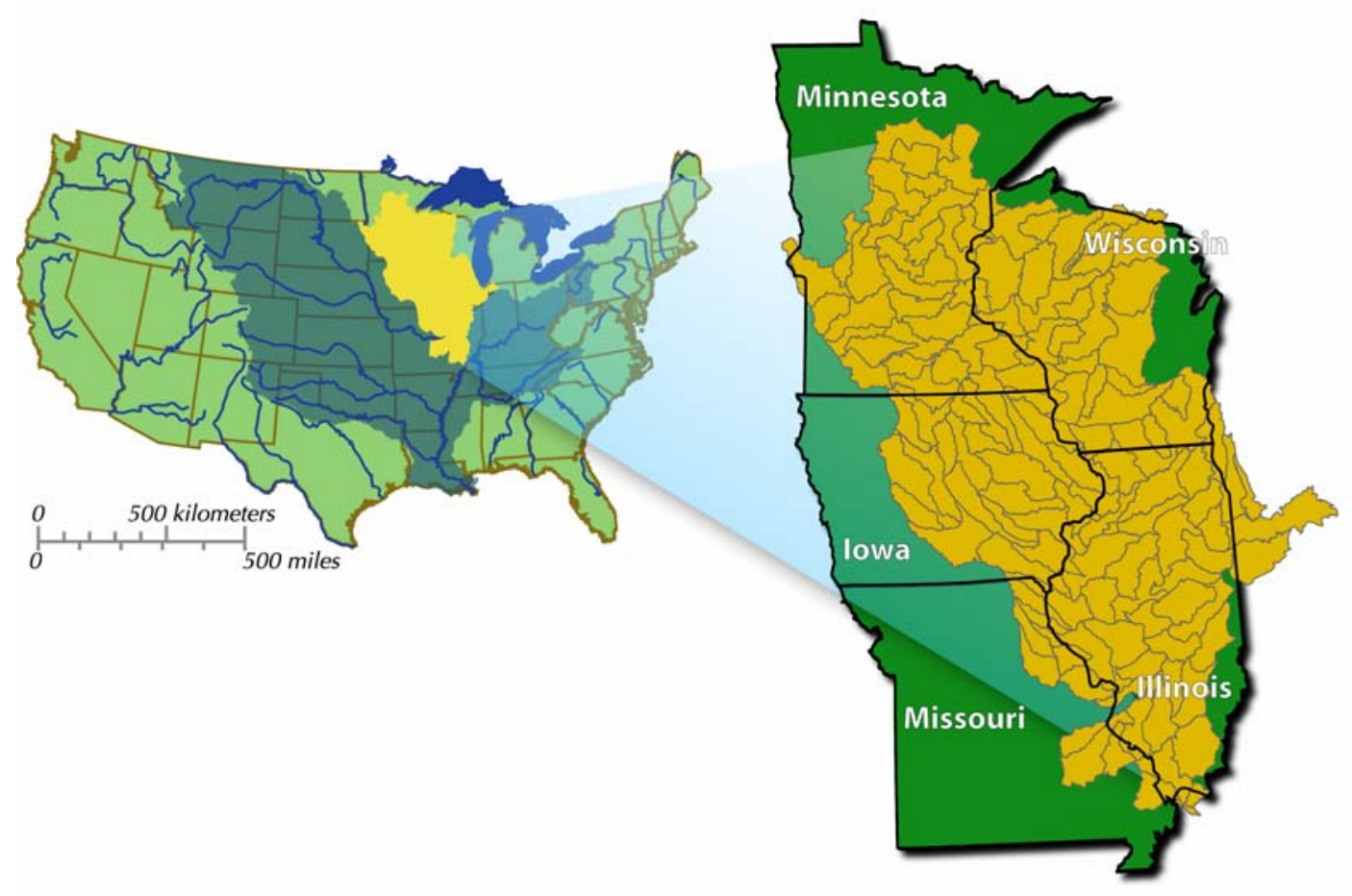

FIGURE 2. The study region-the Upper Mississippi River Basin 
18th sign-up of the CRP). To study the carbon sequestration potential and co-benefits associated with conversion of cropland to perennial grasses, we rely upon the National Resource Inventory (NRI) (USDA-NRCS 1997) to identify the basic characteristics of the land base, including the cropping history in the region. To assess the costs of additional conversion, we obtained agricultural land rental rates from state extension agencies. Data from five states in the region were collected. The average rental rates in Iowa and Illinois are above $\$ 120$ per acre. Missouri and Wisconsin have average rates of about $\$ 60$ per acre and Minnesota's rental rate is about $\$ 85$ per acre. There are also notable variations within state boundaries.

To assess the carbon benefits and co-benefits of converting cropland to perennial grasses in this region, it is necessary to have an estimate of the carbon gains and other environmental benefits from this conversion. To obtain these numbers, we draw on a commonly used field-scale model, the Environmental Policy Integrated Climate (EPIC) model. We use version 3060, which has updated carbon sequestration routines. ${ }^{3}$ EPIC predicts the 10-year change in carbon sequestration at each NRI point in our data set associated with a change from the existing crop choice and rotation to perennial grass cover. We also use EPIC to estimate the average annual reduction in erosion, nitrogen runoff, and leaching at each point if it were converted to perennial grasses. These latter three environmental indicators are our measures of co-benefits associated with carbon sequestration. The average annual carbon sequestration rate in the region from conversion is just under half a ton per acre. Next, we present the empirical characteristics of cobenefits and their implications on policy design in our study region.

\subsection{The Characteristics of Co-benefits in the Study Region}

As noted in section 2.2 earlier, there is not necessarily a linear or smooth relationship between the "supply" or marginal cost of co-benefits and carbon sequestration. Here, we use three sets of figures to illustrate such a relationship empirically: the marginal cost of carbon sequestration versus the marginal cost of its co-benefits, the marginal co-benefits associated with each ton of carbon sequestered versus carbon prices, and the total amount of carbon sequestered versus the total amount of other environmental benefits achieved.

Since carbon and its co-benefits are measured in physical quantities that are not directly comparable, we compute the average ranking of each field in providing overall 
environmental benefits. To derive an average ranking of benefits (ARB), we first rank each field (NRI point) based on individual benefit indicators: carbon sequestration, reduction in erosion, runoff, and leaching (i.e., the field that achieves the highest level of carbon sequestered per dollar receives a rank of " 1 " for that indicator, etc.). The ARB is just the average of the rankings of the four environmental indicators. While this does not completely avoid the problem of comparability, it transparently places an equal weight on the ranking of each environmental measure; one can think of this as one of many environmental indices that could be constructed. The ARB is actually quite similar to the environmental benefit index (EBI) used in the evaluation of applications to the CRP. The only differences are that the EBI takes into account the cost factor and other environmental indicators (e.g., wildlife habitat, air quality zones, and enduring environmental benefits) and that different weights are given for different environmental factors in the EBI.

Figures 3 and 4 illustrate the marginal costs of carbon sequestration and erosion reduction. In Figure 3, the fields are sorted by the marginal cost of sequestration, so that by construction the marginal cost of carbon is upward sloping. In a carbon market, fields that correspond to the left part of the diagram will be more competitive and thus are more likely to participate. In Figure 4, the fields are sorted by the ARB where fields on the left

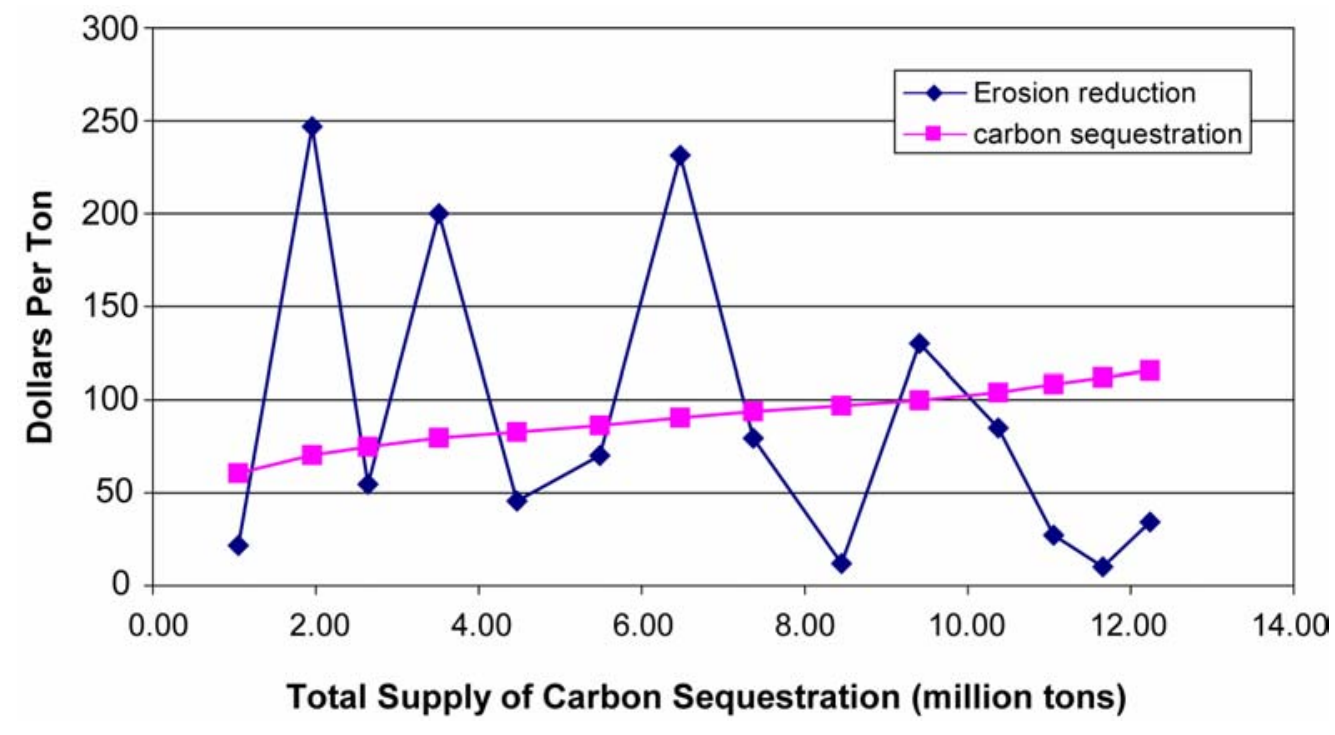

FIGURE 3. Marginal cost of carbon versus the marginal cost of erosion reduction 


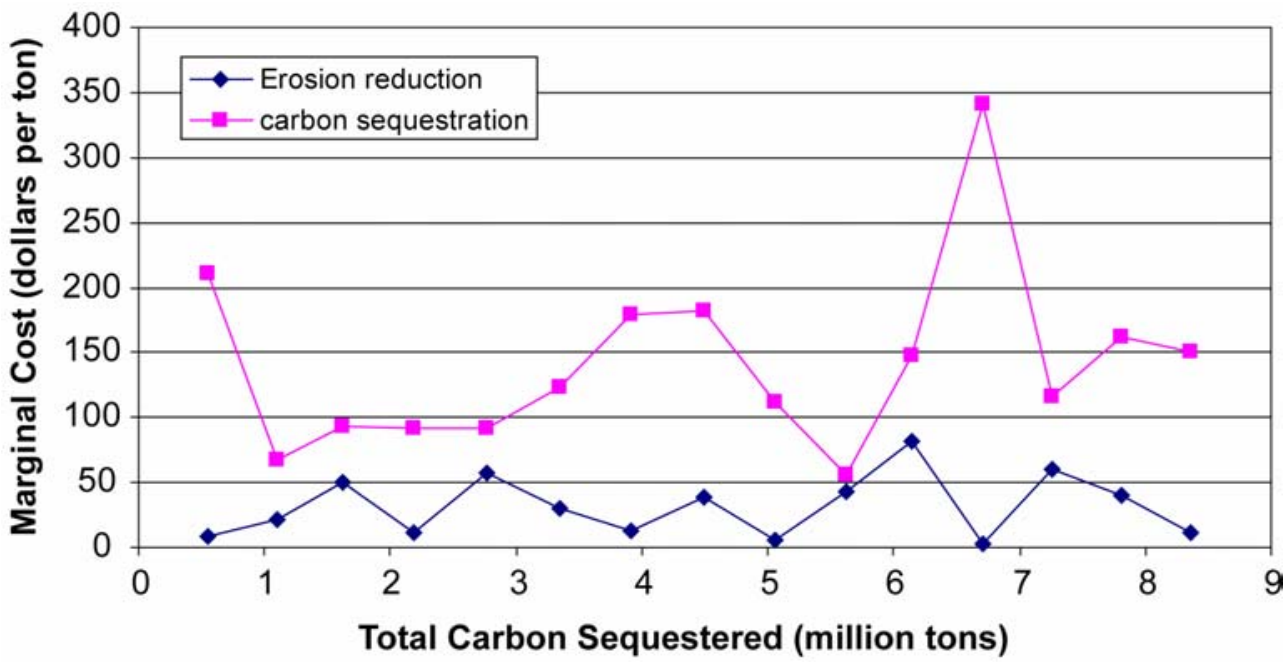

FIGURE 4. The marginal cost of carbon versus the marginal cost of erosion reduction under an ARB-based program

will be more competitive in a program that takes into account these four benefits. The two figures show that there is no obvious correlation among the marginal costs. This implies that when policymakers care more about one benefit or put different weights on the components of a bundle of benefits, different fields will participate and different quantities of benefit might be achieved in terms of each environmental indicator.

In Figure 1, the co-benefits are assumed to be roughly constant for various levels of marginal cost of sequestration (or carbon supply). However, our empirical results demonstrate a completely different story, as illustrated by Figure 5 where the co-benefits of erosion reduction (measured as tons of reduction for every ton of carbon sequestered) show a zigzag pattern within an overall increasing trend. In other words, as more parcels are enrolled, co-benefits in terms of erosion reduction may be high or low, although the co-benefits appear to be increasing as carbon price increases. This would imply that the dashed line for sequestration in Figure 1 (the one that goes upward from left to right) would not be as smooth as shown in the figure.

However, with some degree of aggregation, the marginal co-benefits tend to smooth out in terms of either individual co-benefits or the ARB as shown in Figures 6 and $7 .^{4}$ In the two figures, both the horizontal and vertical axes represent the cumulative sum of the benefits indicated as more and more land area participates. Each dot in the plots represents 500 more fields (NRI points) than the previous dot. In Figure 6, the curve is 


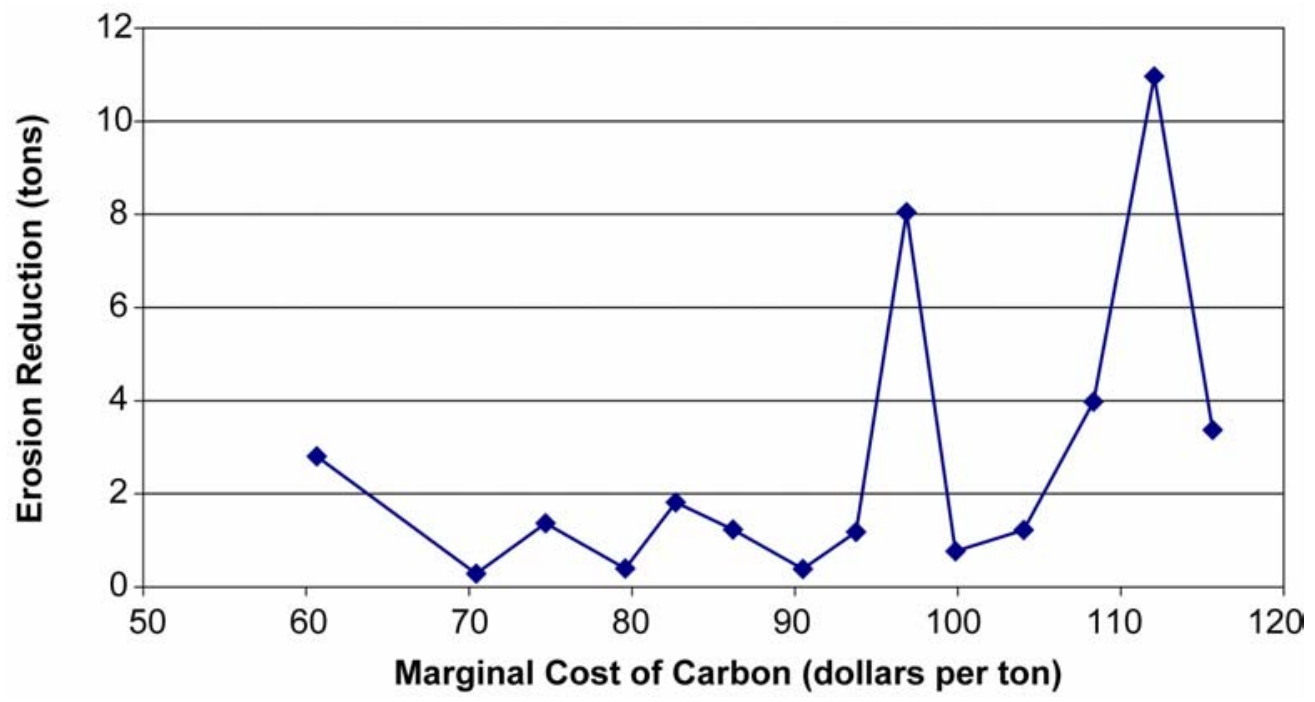

FIGURE 5. Marginal co-benefits in terms of erosion reduction at various carbon prices

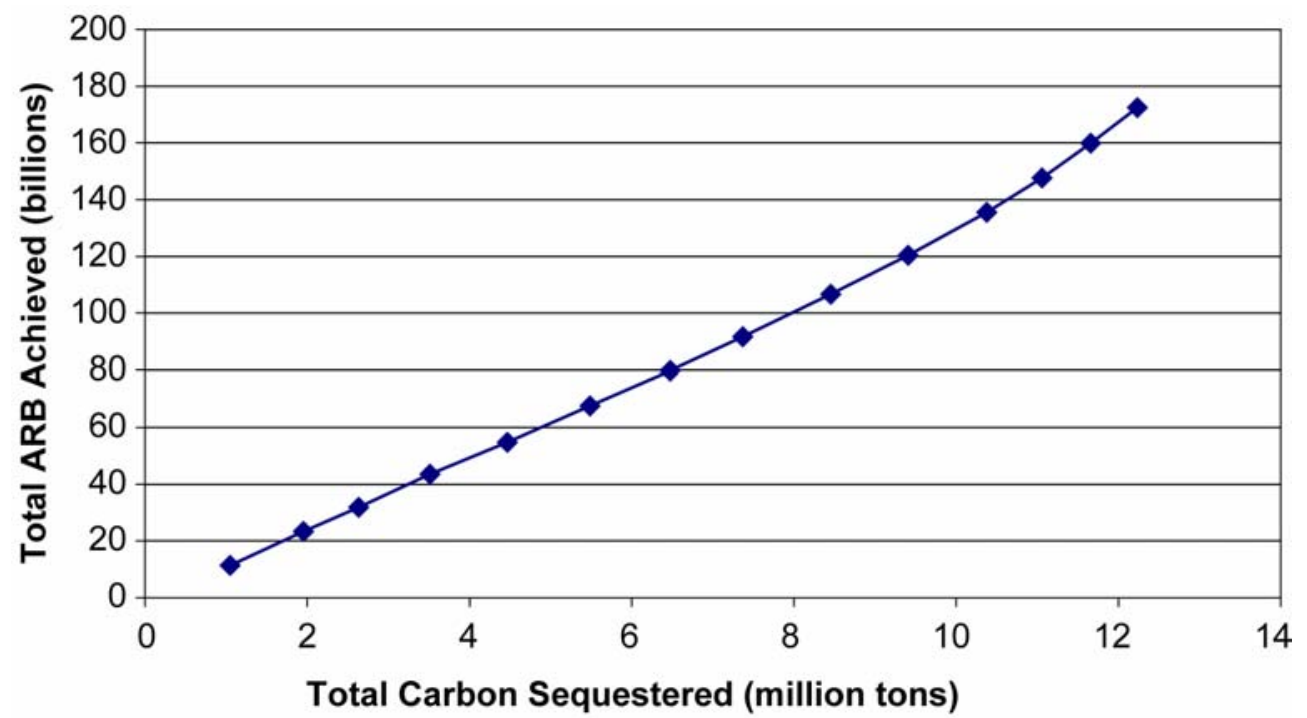

FIGURE 6. Total ARB achieved versus total carbon supply in an efficient carbon market

approximately linear, which implies that the marginal costs of co-benefits are close to a multiple of the marginal costs of carbon at various carbon levels when fields are considered in groups of similar marginal cost of carbon sequestration. An approximate linearity is also observed in Figure 7 even though the linear relationship is between ARB and erosion reduction. The eventual implication of such linear structure will depend on how aggregation takes place when carbon sequestration is implemented. 


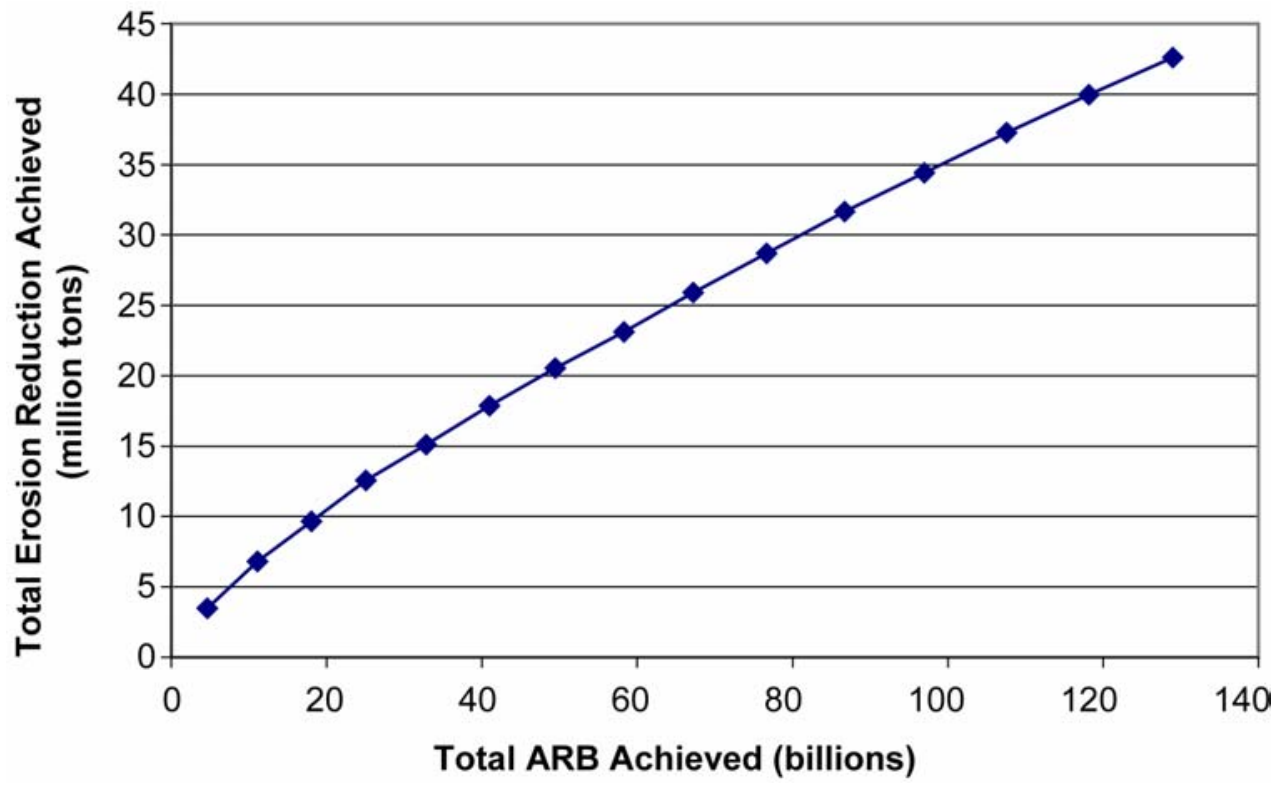

FIGURE 7. Total erosion reduction achieved versus total ARB achieved under an efficient conservation program targeting ARB

\subsection{The Different Outcomes of Carbon Programs and Conservation Programs When They Are Designed and Implemented Separately}

We consider two kinds of policy outcomes: the distribution of the areas enrolled, and the total amount of carbon and its distribution achieved under the policies. The two policies we compare are a competitive carbon market and a competitive conservation program that maximizes the ARB. In this section, we compare the policies as exclusive options; that is, we consider carbon markets without the presence of conservation programs and vice versa. Figure 8 illustrates the difference in the distribution of the areas enrolled and the distribution of the carbon sequestered. To make meaningful comparisons, both policies are constrained to have the same total amount of land placed into retirement. The total amount of various environmental benefits is presented in Table 1 for four scenarios that vary the percentage of total retired cropland. The percentages range from 5 to 11 percent.

The foregoing analysis implies that different areas will participate in a carbon market than will participate in a conservation program. As demonstrated by the top two maps in Figure 8 , this is in fact the case in our study region. The area that has the most acreage is in the north of the UMRB for the carbon market policy. However for the policy based on 

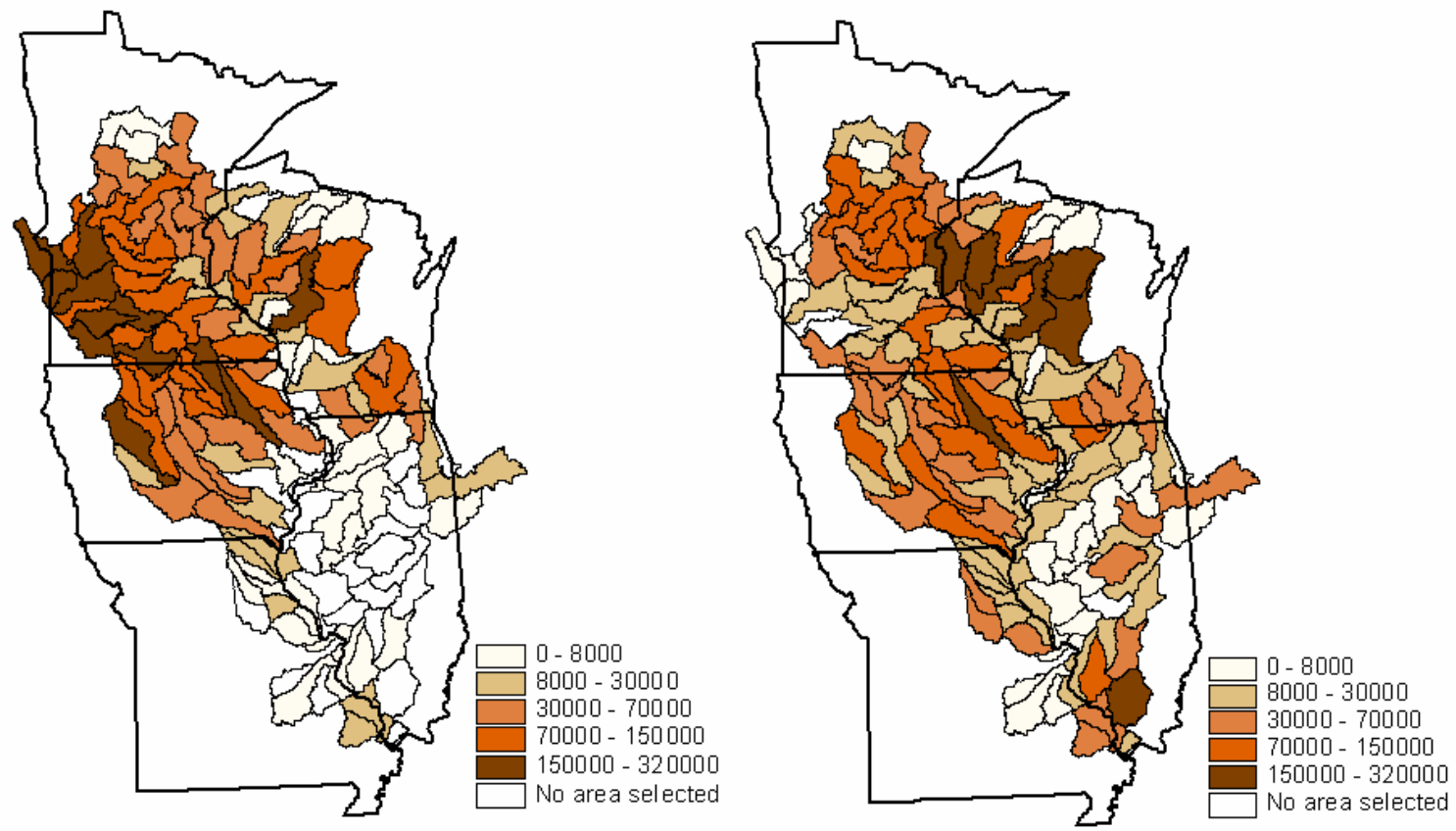

C. Carbon sequestration under a carbon market

D. Carbon sequestration based on the ARB
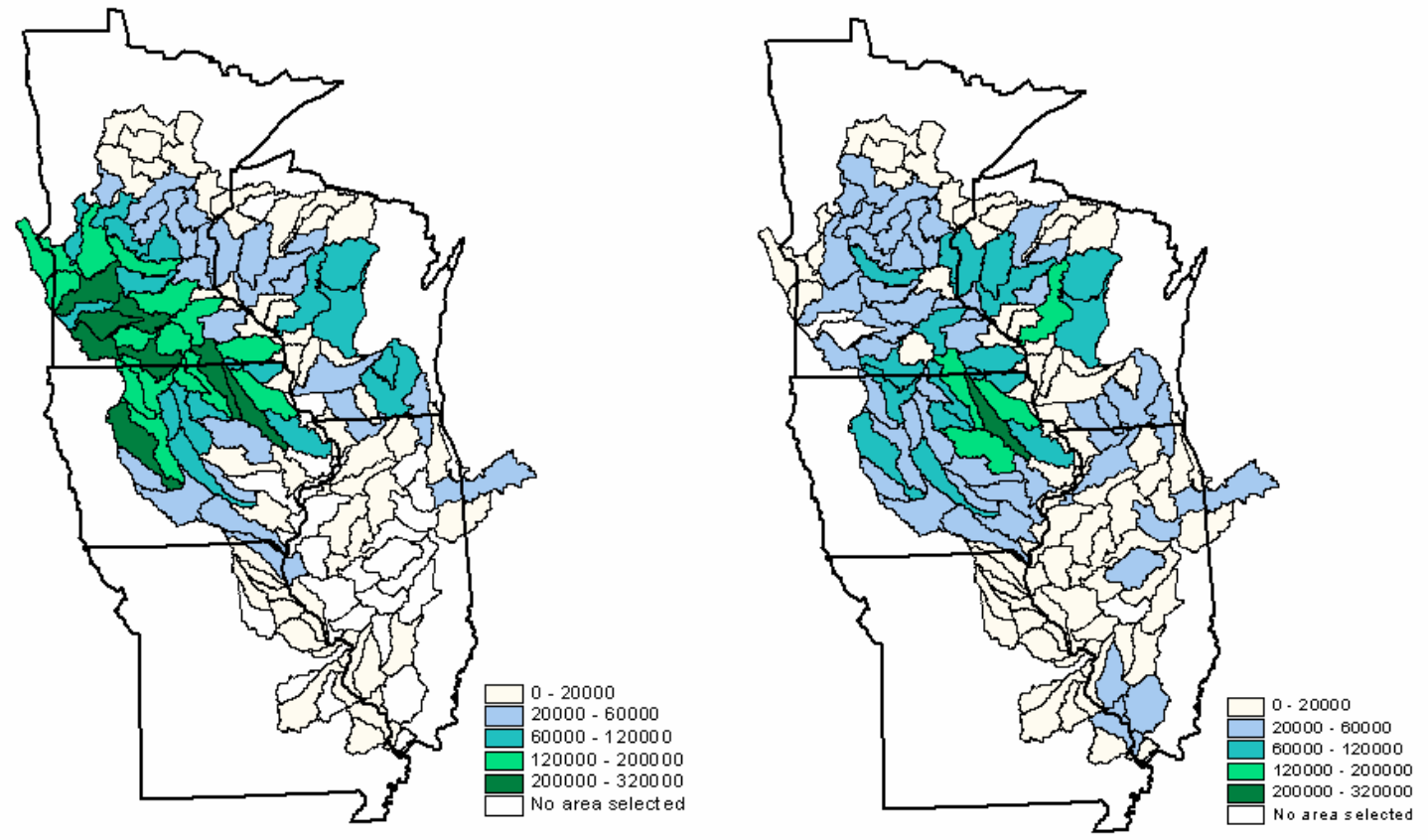

FIGURE 8. Distributions of land enrolled and carbon sequestered 
TABLE 1. Aggregate environmental benefits under carbon markets and a policy based on average ranking of benefits (ARB)

\begin{tabular}{lccccc}
\hline \multicolumn{1}{c}{ Policies } & $\begin{array}{c}\text { Land } \\
\text { Enrolled } \\
(\%)\end{array}$ & $\begin{array}{c}\text { Carbon } \\
\text { sequestration } \\
\text { (million tons) }\end{array}$ & $\begin{array}{c}\text { Erosion } \\
\text { reduction } \\
\text { (million tons) }\end{array}$ & $\begin{array}{c}\text { N runoff } \\
\text { reduction } \\
\text { (million kgs) }\end{array}$ & $\begin{array}{c}\text { N leaching } \\
\text { reduction } \\
\text { (million kgs) }\end{array}$ \\
\hline C markets & 5 & 3.29 & 3.75 & 5.18 & 30.13 \\
ARB based & 5 & 1.85 & 10.93 & 8.25 & 34.53 \\
C markets & 7 & 4.77 & 5.60 & 7.45 & 46.60 \\
ARB based & 7 & 2.79 & 15.21 & 11.61 & 50.95 \\
C markets & 9 & 6.20 & 7.45 & 9.63 & 64.55 \\
ARB based & 9 & 3.73 & 19.62 & 14.68 & 68.17 \\
C markets & 11 & 7.52 & 9.43 & 11.82 & 83.14 \\
ARB based & 11 & 4.67 & 24.01 & 17.67 & 83.07 \\
\hline
\end{tabular}

$\mathrm{ARB}$, the area tends to be evenly spread across the region. The different distribution of the acreage leads directly to carbon sequestration distributions that vary following a similar pattern, as shown in the bottom two maps in Figure 8. Consideration of four hypothetical program sizes, corresponding to different percentages of total land area, indicates that the qualitative results are not overly sensitive to carbon prices (assuming an inverse relationship to land area) within the range represented in Figure 3.

Different distributions in land areas and carbon sequestration do not necessarily mean different total carbon benefits, as demonstrated in Feng 2005. However, in this case, notable differences occur. Note that for all four percentages of land area enrolled, the ARB-based policy achieves at least 1.5 times more erosion reduction than does the carbon market. This implies that, in order for a carbon-based policy to be socially preferred to the ARB-based policy, carbon prices would have to be at least 1.5 times as high as the monetary value the society puts on erosion reduction. ${ }^{5}$ This does not include the benefits provided by nutrient reduction in nitrogen runoff and leaching.

\subsection{Implementation of Conservation Programs in the Presence of Carbon Markets}

As discussed in the introduction, some major conservation policies already make payments to farmers for the adoption/maintenance of conservation practices that sequester carbon. Thus, a challenge of policy design will be to address the interactions between 
conservation program payments and carbon markets when carbon sinks generate offsets. Several interesting questions arise. First, will a carbon offset system and conservation programs compete for the same land? If so, the benefit of coordinating the two instruments is likely to be large. From maps A and B in Figure 8, however, it is apparent that sub-regions in the study area likely to become major players in a carbon market are different from those likely in a conservation program. Thus, competition for land may not be too significant, at least in this region.

A second question concerns the amount of other benefits that can be achieved under each program when both programs exist. Table 1 indicates the magnitude of co-benefits (e.g., erosion reduction and runoff reduction) that can be achieved in addition to carbon under an offset program, and the carbon sequestration that can be achieved with other environmental benefits under conservation programs. Although the difference can be large, it is worth noting that both systems have the potential to achieve improvements in all environmental indicators. Thus, it is likely that we will achieve a significant amount of improvement in all environmental indicators when both programs exist.

The last question we consider is who will claim the ownership of externalities, and therefore reap any financial rewards, under either an offset program or a conservation program. In an offset program, carbon is the benefit that generates market value while other benefits such as erosion reduction and nutrient runoff do not. In this case, the externalities will have little or no monetary value to a farmer/landowner. ${ }^{6}$ On the other hand, for a parcel that is under a conservation program, carbon accumulated in the soil will have a market value, which can be realized in the offset program. Will farmers be allowed to sell carbon and keep the revenue, even though they have received payment from the conservation program? Given the long history of income support for farmers in developed countries, the answer may be yes. ${ }^{7}$ However, the government could choose to support farmers in another way: it could claim the carbon from all enrolled land, aggregate it, sell it in the carbon market, and then return the revenue by enrolling more land or by paying farmers more for each enrolled land parcel. Depending on the carbon prices, this could have a big impact on conservation program costs. From Table 1, when carbon prices are high enough, an offset program can generate as much revenue annually as the expenditures on land set-aside in the region: Assuming an enrollment of 5 percent of land 
area, the total carbon sale would be worth over $\$ 300$ million at a carbon price of $\$ 100$ per ton, which exceeds the current CRP expenditure in this region.

Of course, a farmer may choose not to participate in a conservation program. In this case, there is no dispute about the ownership of the carbon sequestered by this farmer. One approach for the design of conservation programs could be to give farmers the option of retaining the ownership of the carbon sequestered in their fields that results from enrollment in a conservation program. In this case, farmers would decide between lowering their bid (for government payment) while retaining the right to sell the carbon sequestered or make a higher bid but give up the right to sell their carbon.

\section{Discussion/Conclusions}

Many countries are considering plans to mitigate climate change by reducing their net contribution to atmospheric GHG concentrations. Those that have ratified the Kyoto Protocol will have to decide whether to adopt Article 3.4 of the agreement, which is optional and incorporates additional activities involving forest and agricultural management. Those countries that have not ratified the Protocol do not have an international obligation to reduce their GHG emissions during the initial commitment period (20082012), but they will have the opportunity to consider joining the agreement after this period. The policy design issues related to co-benefits should be an important consideration when countries make these decisions.

In this paper, we have demonstrated that the relationship between carbon and its associated co-benefits will affect the efficiency of policy instruments designed for carbon sequestration. It is vital that policymakers understand how these instruments affect each other, as (1) there is already a multitude of existing conservation programs, which result in significant carbon sequestration in many countries; and (2) nascent carbon markets are emerging, even in countries that have not ratified the Kyoto Protocol (a notable example is the United States). In particular, the efficient level and location of carbon sequestering practices depend on more than just the total amount of carbon to be sequestered and the cost of doing so: the magnitude and location of cobenefits are also critical. Finally, we have also illustrated in this paper how farmers/landowners might be affected financially and how the effects would differ for different farmers/landowners when different policies are used. 


\section{Endnotes}

1. In this pilot project, the credit rates for continuous conservation tillage and permanent grass cover are 0.5 and 0.75 metric tons $\mathrm{CO}_{2}$ equivalent per acre per year, respectively.

2. With aggregating, the analysis of the Pareto efficiency of a well-functioning free market will be similar to that in section 2.1, although the analysis will be in groups on the sequestration side. When co-benefits also accrue from emission reductions, an analogous condition can be derived.

3. For further information, see Feng et al. 2004 and Izaurralde et al. 2005.

4. That the magnitude of the sum of ARB seems unusually large is due to two factors: (1) how the ARB is defined, and (2) the fact that there are over 40,000 fields (NRI points) being ranked. Taking summation of the ARBs over thousands of fields magnifies the size.

5. This, of course, assumes that the carbon market prices accurately reflect the social value of carbon reductions.

6. A farmer may derive non-pecuniary benefit from environmental improvement in general. In addition, a farmer might benefit directly if other environmental improvements are associated with increased land productivity.

7. Indeed the U.S. Department of Agriculture's National Resources Conservation Service has indicated that it views any carbon sequestered resulting from previous CRP programs to be the property of the landowner. In the pilot project sponsored by the Iowa Farm Bureau, farmers are considered to have the ownership of carbon sequestered in fields under the CRP (Iowa Farm Bureau 2005). 


\section{References}

Burtraw, D., A. Krupnick, K. Palmer, A. Paul, M. Toman, and C. Bloyd. 2003. “Ancillary Benefits of Reduced Air Pollution in the U.S. from Moderate Greenhouse Gas Mitigation Policies in the Electricity Sector." Journal of Environmental Economics and Management 45: 650-73.

Butt, T.A., and B.A. McCarl. 2004. "Farm and Forest Carbon Sequestration: Can Producers Employ It to Make Some Money?" Choices, Fall, pp. 27-31.

Feng, H. 2005. "The Dynamics of Carbon Sequestration and Alternative Carbon Accounting, with an Application to the Upper Mississippi River Basin." CARD Working Paper 05-WP 386. Center for Agricultural and Rural Development, Iowa State University.

Feng, H., L.A. Kurkalova, C.L. Kling, and P.W. Gassman. 2004. "Environmental Conservation in Agriculture: Land Retirement versus Changing Practices on Working Land." CARD Working Paper 04-WP 365. Center for Agricultural and Rural Development, Iowa State University.

Feng, H., J. Zhao, and C. Kling. 2002. "The Time Path and Implementation of Carbon Sequestration." American Journal of Agricultural Economics 84(1): 134-49.

Follett, R.F., J.M. Kimble, and R. Lal. 2001. The Potential of U.S. Grazing Lands to Sequester Carbon and Mitigate the Greenhouse Effect. Table 16.1, p. 410. New York: Lewis Publishers.

Ikins, P., and T. Barker. 2001. "Carbon Taxes and Carbon Emissions Trading.” Journal of Economic Survey 15(3): 325-76.

Iowa Farm Bureau. 2005. “Carbon Credit Aggregation Pilot Project.” Backgrounder. http://www.iowafarmbureau.com/special/carbon/default.aspx (accessed February 2005).

Izaurralde, R.C., J.R. Williams, W.B. McGill, and N.J. Rosenberg. 2005. "Modeling Soil Organic Carbon Changes in CRP Land and a Long-Term Crop Rotation Trial with EPIC." Working Paper. Pacific Northwest National Laboratory, Richland, WA.

Lal, R., J.M. Kimble, R.F. Follett, and C.V. Cole. 1998. The Potential of U.S. Cropland to Sequester Carbon and Mitigate the Greenhouse Effect. Ann Arbor, MI: Sleeping Bear Press.

McCarl, B.A., and U.A. Schneider. 2001. "Greenhouse Gas Mitigation in U.S. Agriculture and Forestry." Science 294(5551, December): 2481-82.

Plantinga, A.J., and J. Wu. 2003. "Co-benefits from Carbon Sequestration in Forests: Evaluating Reductions in Agricultural Externalities from an Afforestation Policy in Wisconsin." Land Economics 79(1): 74-85.

Reedy, H. 2003. "Feasibility Assessment of Afforestation for Carbon Sequestration: Exploring Options for Aggregating and Selling Afforestation Carbon Credits from Small Landowners.” A report prepared by Reedy Ventures, Smithers, British Columbia, Canada, for Canadian Forest Service, Pacific Forestry Centre, Federation of BC Woodlot Associations, and Canadian Landowners. 
Sedjo, R.A., and G. Marland. 2003. "Inter-trading Permanent Emissions Credits and Rented Temporary Carbon Emissions Offsets: Some Issues and Alternatives. Climate Policy 2(3): 435-44.

Thomassin, P. 2003. "Canadian Agriculture and the Development of a Carbon Trading and Offset System. American Journal of Agricultural Economics 85(5): 1171-77.

U.S. Department of Agriculture, National Resources Conservation Service (USDA-NRCS). 1997. National Resource Inventory. Data files. http://www.nrcs.usda.gov/technical/nri/1997. 